* Doutoranda em Direito pela Universidade do Vale do Rio dos Sinos - UNISINOS, com período sanduíche na Universidad de Sevilla (Espanha). Bolsista CAPES (PDSE - Proc. $\mathrm{n}^{\circ}$ 1267313-7). Mestre e Graduada em Direito pela Universidade de Santa Cruz do Sul UNISC. Professora na Faculdade de Direito de Santa Maria - FADISMA. Integrante dos Grupo de Pesquisa "Estado e Constituição", vinculado ao CNPq. Advogada. E-mail: tassia gervasoni@hotmail.com

** Doutorando e Mestre em direito pela Universidade de Santa Cruz do Sul - UNISC. Especialista em Direito Civil pela Faculdade Meridional - IMED. Integrante do Grupo de Pesquisa "Intersecções jurídicas entre o público e o privado", coordenado pelo Pós-Dr. Jorge Renato dos Reis, vinculado ao CNPq. Professor das disciplinas de Direito Constitucional e Introdução ao Estudo do Direito. Advogado. E-mail: iuribolesina @gmail.com

\section{Os direitos sociais como elemento de sustentabilidade $e$ fundamentação do Estado democrático de direito}

\author{
THE SOCIAL RIGHTS AS A SUSTAINABILITY \\ ELEMENT AND FOUNDATION OF DEMOCRATIC RULE \\ OF LAW \\ * Tássia Aparecida Gervasoni \\ ** Iuri Bolesina
}

Resumo: Os direitos sociais expressam o desejo de realização de uma igualdade que seja substancial. Contudo, verifica-se ainda grande resistência não só ao reconhecimento do status de direito fundamental a esses direitos como também à vinculação imediata e direta do Estado na sua prestação. A partir disso, o presente trabalho pretende apresentar e revisitar algumas dessas críticas no sentido de demonstrar a fundamentalidade dos direitos sociais, bem como sua inegável importância ético-jurídica na estruturação e sustentação do próprio Estado Democrático de Direito.

Palavras-chave: Direitos humanos. Direitos sociais. Fundamentação ético-jurídica. Sustentabilidade democrática. Estado Democrático de Direito.

Abstract: The social rights express the desire to carry out of an equality that is substantial. However, there is still great resistance not only the recognition of the fundamental right status of to those rights as well as the immediate and direct linking of the state in its provision. From this, the present work aims to deconstruct some of these criticisms to demonstrate the fundamentality of social rights and its undeniable ethical and legal importance in structuring and support of their own democratic state.

Keywords: Human rights. Social rights. Ethical and legal reasons. Democratic sustainability. Democratic Rule of Law. 
“A regra da igualdade não consiste senão em quinhoar desigualmente aos desiguais, na medida em que se desigualam. Nesta desigualdade social, proporcionada à desigualdade natural, é que se acha a verdadeira lei da igualdade [...]. Tratar com desigualdade a iguais, ou a desiguais com igualdade, seria desigualdade flagrante, e não igualdade real.”

Rui Barbosa, Oração aos Moços.

\section{INTRODUÇÃO}

Ao consagrar como lema, em 1789, os ideais de liberdade, igualdade e fraternidade, os revolucionários franceses profetizaram com exatidão o percurso a ser duramente trilhado pelos direitos fundamentais. Os primeiros a alcançarem reconhecimento, logo na primeira forma de Estado Constitucional, foram os direitos destinados à consagração da liberdade. Depois, só na segunda metade do século XIX, ganharam espaço os direitos sociais, visando efetivar a promessa de igualdade, uma igualdade, enfim, material. Com a devastação legada pela segunda guerra mundial a consciência generalizada de que algo precisava ser feito para preservar a própria humanidade fez destacar-se, finalmente, uma preocupação com a fraternidade. E, assim, todos poderiam ter vivido livres, iguais e solidários para sempre. Não? Então, o que deu errado?

Apesar do truísmo, a consagrada frase de Norberto Bobbio (1982) segundo a qual "o problema grave do nosso tempo, com relação aos direitos humanos, não é mais o de fundamentá-los e sim o de protegê-los” sinaliza uma resposta. ${ }^{1}$ Também Costas Douzinas poderia apontar uma hipótese ao constatar o verdadeiro abismo que se abriu entre a teoria e a prática dos direitos humanos nos últimos séculos. ${ }^{2}$

Em relação aos direitos sociais, expressão de uma sonhada igualdade substancial, as perspectivas são tão ou mais desoladoras. Verifica-se ainda grande resistência não só ao reconhecimento do status de direito fundamental aos direitos sociais, mas também à vinculação imediata e direta do Estado na sua prestação.

A partir disso, o presente trabalho pretende desconstruir algumas dessas oposições no sentido de demonstrar a fundamentalidade dos direitos sociais, bem como sua inegável importância ético-jurídica na estruturação do próprio Estado Democrático de Direito, do qual constituiu elemento e condição de sustentabilidade.

1 BOBBIO, Norberto. El tiempo de los derechos. Madrid: Sistema, 1991.

2 DOUZINAS, Costas. $O$ fim dos direitos humanos. São Leopoldo: Unisinos, 2009. 
Para tanto, procede-se, num primeiro momento, a um breve excurso histórico quanto à evolução dos direitos fundamentais, visando compreender, sobretudo, as condições de surgimento dos chamados direitos de segunda dimensão. Na sequência, apresentam-se e rebatem-se importantes críticas que lhes são imputadas, para então, finalmente, apresentar a fundamentação pretendida.

\section{DIREITOS FUNDAMENTAIS SOCIAIS? DE ONDE VIERAM...}

A atual compreensão acerca dos direitos sociais é resultado de uma série de transformações ocorridas no tempo, as quais podem ser analisadas em certa relação de causa e efeito com o desenvolvimento da própria sociedade e do Estado Constitucional, bem como quanto ao recrudescimento das noções de Constituição e direitos fundamentais.

Dentre as diversas teorias que se ocupam de justificar essa relação, uma das mais difundidas e aceitas é a que divide os direitos fundamentais em gerações. Duas ressalvas, contudo, devem ser antecipadas. A primeira quanto à própria designação “geração”, preterida por respeitável doutrina por transmitir a equivocada ideia de superação de uma fase pela seguinte, quando, na verdade, trata-se de um processo contínuo e aberto, de soma e acumulação. ${ }^{3}$ Daí a opção, que será seguida doravante, pelo termo “dimensões”. A segunda observação, mas nem por isso menos importante, quase logicamente decorrente da primeira, concerne ao caráter meramente didático da segmentação feita em relação à evolução histórica dos direitos fundamentais, já que o processo versado, reitera-se, é de continuidade.

Feito isso, para confirmar a existência da imbricação apontada entre a evolução estatal e as reivindicações sociais, faz-se um convite à observação do surgimento do Estado Moderno: dentre os fatores determinantes a sua emergência estava a necessidade de um Estado forte, centralizador, diante da fragmentação e da instabilidade de poder verificada nesse período; a figura estatal, nesses moldes, aparece, então, como uma perspectiva positiva e necessária de estabilização social; de certa forma, a resposta encontrada, nesse contexto, foi o advento do Estado Absolutista (e, corolário, a reunificação do poder na figura do rei). ${ }^{4}$

\footnotetext{
${ }^{3}$ Por todos, SARLET, Ingo Wolfgang. A eficácia dos direitos fundamentais: uma teoria geral dos direitos fundamentais na perspectiva constitucional. 10. ed. Porto Alegre: Livraria do Advogado, 2009.

${ }^{4}$ No mesmo sentido, DALLARI, Dalmo de Abreu. Elementos de teoria geral do Estado. 30. ed. São Paulo: Saraiva, 2011.
} 
Na sequência histórica, para a superação deste modelo o descontentamento parte, sobretudo, da classe burguesa, que, embora detentora de poderio econômico via-se despida de poder e influência políticos, diante de sua concentração na figura do monarca (além do desagrado em relação aos privilégios concedidos à nobreza e ao clero). Daí que a Revolução Francesa de 1789 (ou, Revolução burguesa) marca a suplantação dessa fase, dando suporte ao Estado Liberal, em que o direito passa a dominar a política e o poder do Estado é reduzido, cabendo-lhe, basicamente, a garantia da liberdade individual.

A partir disso, no marco histórico do período liberal, berço da figura da Constituição - enquanto documento jurídico-positivo - e também período de consolidação do positivismo jurídico, assiste-se à consagração da primeira dimensão dos direitos fundamentais, correspondente ao primeiro ideal da Revolução Francesa de 1789, Liberdade.

As Constituições liberais constituem um documento eminentemente jurídico, cuja prerrogativa maior, conforme já salientado, é a imposição de limites ao Estado e a garantia dos direitos individuais negativos. Estes são os chamados direitos de primeira dimensão, os quais, ao menos no âmbito de seu reconhecimento nas primeiras Constituições escritas, são o produto peculiar do pensamento liberal-burguês do século XVIII, de marcado cunho individualista, surgindo e afirmando-se como direitos do indivíduo frente ao Estado (direitos de defesa), daí a especificação “direito negativos”. 5

Ocorre que esse modelo gerou desigualdades sociais profundas, pois, ao contrário do suposto, a liberdade que garantia uma igualdade formal não assegurou a igualdade material, cuja busca culminou no surgimento do Estado Social. Assim, em relação, especificamente, ao surgimento deste último e das novas exigências sociais, ressalta-se que a partir das flagrantes desigualdades geradas pela noção de igualdade jurídica, entregue ao livre desenvolvimento do mercado, começam os movimentos sociais a reclamar a atuação por parte do Estado, no sentido de regulação de certas distorções provocadas pelo modelo anterior (liberal-burguês). ${ }^{6}$

\footnotetext{
SARLET, Ingo Wolfgang. A eficácia dos direitos fundamentais: uma teoria geral dos direitos fundamentais na perspectiva constitucional. 10. ed. Porto Alegre: Livraria do Advogado, 2009.

${ }^{6}$ BÖCKENFÖRDE, Ernst-Wolfgang. Estudios sobre el Estado de Derecho y la Democracia. Madrid: Trotta, 2000. Em uma perspectiva mais crítica e menos otimista, AVELÃS NUNES, António José. As voltas que o mundo dá... Reflexões a propósito das aventuras e desventuras do estado social. Rio de Janeiro: Lumen Juris, 2011.p. 29-31: "Falhado aquele pressuposto [liberal]que justificava a tese de que o estado deveria estar separado da sociedade e da economia - impôsse a necessidade de confiar ao estado (ao estado capitalista) novas funções, no plano de economia e no plano social. [...] As lutas da nova classe operária [...] constituíram a forma mais visível e mais
} 
Ao Estado Social atribui-se o surgimento dos chamados direitos de segunda dimensão (direitos econômicos, sociais e culturais), cuja nota distintiva é a sua dimensão positiva, já que reclamam do Estado um comportamento ativo na realização da justiça social. Isso se dá em decorrência dos impactos da industrialização e os graves problemas sociais e econômicos que a acompanharam, deixando evidente que a consagração formal da liberdade e da igualdade não garantia o seu efetivo gozo. ${ }^{7}$

De acordo com José Murilo de Carvalho, “se os direitos civis garantem a vida em sociedade, se os direitos políticos garantem a participação no governo da sociedade, os direitos sociais garantem a participação na riqueza coletiva” incluindo os direitos à educação, trabalho, salário justo, saúde, aposentadoria. Em tese, reconhece o autor, são direitos que podem existir independentemente dos direitos civis e políticos, contudo, isso tornaria o seu conteúdo e alcance tendentes à arbitrariedade. ${ }^{8}$

Corroborando esse entendimento, Rosanvallon propõe o resgate do espírito de igualdade tal como forjado nas revoluções americana e francesa, entendida "[...] principalmente como una relación, como una manera de hacer sociedad, de producir y de dar vida a lo común. Se consideró una cualidad democrática y no solamente una medida de distribución de la riqueza.”9

De qualquer modo, em apertada síntese, "os direitos sociais permitem às sociedades politicamente organizadas reduzir os excessos de desigualdade produzidos pelo capitalismo e garantir um mínimo de bem-estar para todos. A idéia (sic) central em que se baseiam é a da justiça social.” ${ }^{10}$

Finalmente, então, a partir da sua conformação como social, o Estado de Direito acrescenta àquela juridicidade liberal um conteúdo social, de modo que se soma à concepção até então predominante de restrição à atividade

profunda de contestação do direito clássico (do direito burguês). [...] Por isso foi mais fácil avançar para soluções de compromisso que implicaram a integração, na nova ordem jurídica do capitalismo, de princípios contrários aos dogmas da ordem liberal, mas, logicamente, não contrários à essência do capitalismo. O qualificativo social, que tempos antes carregava algo de subversivo, assume agora, aos olhos da burguesia, um ar protector e tranqüilizador. [...] O estado democrático e social foi então considerado como o compromisso possível entre os grupos mais radicais (socialistas) do operariado francês e os partidos representativos da pequena burguesia, implicando o reconhecimento, em favor dos trabalhadores, de certos direitos sociais e económicos.”

7 SARLET, Ingo Wolfgang. A eficácia dos direitos fundamentais: uma teoria geral dos direitos fundamentais na perspectiva constitucional. 10. ed. Porto Alegre: Livraria do Advogado, 2009.

${ }^{8}$ CARVAlHO, José Murilo de. Cidadania no Brasil: o longo caminho. 11. ed. Rio de Janeiro: Civilização Brasileira, 2008. p. 10.

9 ROSANVALLON, Pierre. La sociedad de los iguales. Barcelona: 2012. p. 21.

${ }^{10}$ CARVAlHO, José Murilo de. Cidadania no Brasil: o longo caminho. 11. ed. Rio de Janeiro: Civilização Brasileira, 2008. p. 10. 
estatal a ideia de prestações a serem implementadas pelo Estado (promoção de determinadas ações pretendidas pela ordem jurídica), cujo método assecuratório de efetividade passa a ser a lei. Assim, de limitadora do poder estatal, a lei passa a ser, privilegiadamente, no modelo social, um instrumento de ação concreta do Estado ${ }^{11}$, apesar da noção de normas programáticas, que acabou sendo desvirtuada e relativizando o dever de atuação do Estado.

Em outras palavras, as transformações sociais que conduziram ao Estado Social não afetaram o conteúdo jurídico próprio do ideário liberal, mas the agregaram a questão social. Tem-se, assim, "a construção de uma ordem jurídica na qual está presente a limitação do Estado ladeada por um conjunto de garantias e prestações positivas que referem a busca de um equilíbrio não atingido pela sociedade liberal.”12

Já na passagem para o Estado Democrático de Direito ${ }^{13}$, em um contexto de recrudescimento da noção dos direitos fundamentais, por sua vez, a Constituição - que assume uma função principiológica - vê-se ampliada e expandida para abarcar os conteúdos da realidade.

É nesse contexto, ademais, que se fala em direitos de terceira dimensão (direitos de solidariedade e fraternidade), resultantes de novas reivindicações fundamentais do ser humano, geradas, dentre outros fatores, pelo impacto tecnológico, pelo estado crônico de beligerância, bem como pelo processo de descolonização do segundo pós-guerra e suas contundentes conseqüências. A nota distintiva desses direitos reside, basicamente, na sua titularidade coletiva, exigindo esforços e responsabilidades em escala até mesmo mundial para a sua efetivação. ${ }^{14}$

${ }^{11}$ STRECK, Lenio Luiz; BOLZAN DE MORAIS, José Luis. Ciência política e teoria do Estado. 7. ed. 2. tir. Porto Alegre: Livraria do Advogado, 2012.

${ }^{12}$ STRECK, Lenio Luiz; BOLZAN DE MORAIS, José Luis. Ciência política e teoria do Estado. 7. ed. 2. tir. Porto Alegre: Livraria do Advogado, 2012. p. 79.

${ }^{13}$ Complementando, registra-se que para DALLARI, Dalmo de Abreu. Elementos de teoria geral do Estado. 30. ed. São Paulo: Saraiva, 2011. p. 147: "É através de três grandes movimentos político-sociais que se transpõem do plano teórico para o prático os princípios que iriam conduzir ao Estado Democrático: o primeiro desses movimentos foi o que muitos denominam de Revolução Inglesa, fortemente influenciada por Locke e que teve sua expressão mais significativa no Bill of Rights, de 1689; o segundo foi a Revolução Americana, cujos princípios foram expressos na Declaração de Independência das treze colônias americanas, em 1776; e o terceiro foi a Revolução Francesa, que teve sobre os demais a virtude de dar universalidade aos seus princípios, os quais foram expressos na Declaração dos Direitos do Homem e do Cidadão, de 1789, sendo evidente nesta a influência direta de Rousseau."

${ }^{14}$ SARLET, Ingo Wolfgang. A eficácia dos direitos fundamentais: uma teoria geral dos direitos fundamentais na perspectiva constitucional. 10. ed. Porto Alegre: Livraria do Advogado, 2009. 
A doutrina diverge ${ }^{15}$, ainda, acerca da existência de dimensões posteriores às mencionadas, mas que escapam às delimitações aqui estabelecidas. As atenções, no presente estudo, voltam-se de modo especial para a segunda dimensão dos direitos fundamentais.

\section{2 ...E PARA ONDE VÃO? FUNDAMENTAÇÃO ÉTICA E JURÍDICA DOS DIREITOS SOCIAIS NO ESTADO DEMOCRÁTICO DE DIREITO}

De imediato, cumpre assinalar que a Constituição Federal brasileira de 1988 traz a noção de dignidade humana como conceito central da ordem jurídicoconstitucional, notadamente ao elencá-la como fundamento da República Federativa do Brasil. ${ }^{16}$ Nessa condição, todas as ações estatais devem se pautar pela dignidade humana como fim a ser realizado (aliás, cumpre a referência, embora não seja objeto direto do trabalho, de que esse princípio se irradia e vincula também aos particulares). ${ }^{17}$

A significação conceitual de dignidade humana sempre desafiou a doutrina e as dificuldades dessa tarefa praticamente levaram ao consenso de que é mais fácil determinar quando esse princípio é violado, ou o que ele não é, do que encerrá-lo numa definição única (apesar de que ainda isso é difícil). O que se tem bastante claro, em contrapartida, é que a realização da dignidade humana

\footnotetext{
${ }^{15}$ A divergência em questão pode ser sintetizada por um de seus protagonistas, nos termos que seguem: "Ainda no que tange à problemática das diversas dimensões dos direitos fundamentais, é de se referir a tendência de reconhecer a existência de uma quarta dimensão, que, no entanto, ainda aguarda sua consagração na esfera do direito internacional e das ordens constitucionais internas. Assim, impõese examinar, num primeiro momento, o questionamento da efetiva possibilidade de se sustentar a existência de uma nova dimensão dos direitos fundamentais, ao menos nos dias atuais, de modo especial diante das incertezas que o futuro nos reserva. Além do mais, não nos parece impertinente a idéia de que, na sua essência, todas as demandas na esfera dos direitos fundamentais gravitam, direta ou indiretamente, em torno dos tradicionais e perenes valores da vida, liberdade, igualdade e fraternidade (solidariedade), tendo, na sua base, o princípio maior da dignidade da pessoa. Contudo, há que referir, no âmbito do direito pátrio, a posição do notável Paulo Bonavides, que, com a sua peculiar originalidade, se posiciona favoravelmente ao reconhecimento da existência de uma quarta dimensão, sustentando que esta é o resultado da globalização dos direitos fundamentais, no sentido de uma universalização no plano institucional, que corresponde, na sua opinião, à derradeira fase de institucionalização do Estado Social.” SARLET, Ingo Wolfgang. A eficácia dos direitos fundamentais: uma teoria geral dos direitos fundamentais na perspectiva constitucional. 10. ed. Porto Alegre: Livraria do Advogado, 2009. p. 50.

${ }^{16}$ Artigo $1^{\circ}$, da Constituição Federal: "A República Federativa do Brasil, formada pela união indissolúvel dos Estados e Municípios e do Distrito Federal, constitui-se em Estado Democrático de Direito e tem como fundamentos: [...] III - a dignidade da pessoa humana.”

${ }^{17}$ SARLET, Ingo Wolfgang. Dignidade da pessoa humana e direitos fundamentais na Constituição Federal de 1988. 5. ed. Porto Alegre: Livraria do Advogado, 2008. ARAGÃO, Alexandre Santos de. Direito dos serviços públicos. Rio de Janeiro: Forense, 2007.
} 
passa pela efetivação de diversos direitos, os quais, de certa forma, lhe são reconduzidos (ou são dela decorrentes) ${ }^{18}$; dentre esses direitos diretamente vinculados à ideia de dignidade estão, sem dúvida, os direitos sociais.

$\mathrm{Na}$ perspectiva dos direitos humanos essa aparente cisão entre direitos de primeira e segunda dimensão parece superada, ao menos enquanto discurso de efetivação. A Declaração Universal de 1948, responsável pela deflagração do chamado processo de internacionalização do Direito e pela introdução da moderna concepção de direitos humanos os apresenta marcados por duas importantes características: universalidade e indivisibilidade. Universalidade por exigir como requisito à titularidade dos direitos em questão apenas a condição de pessoa humana; e, indivisibilidade, ponto extremamente importante à fundamentação que se pretende construir aqui, porque o catálogo dos direitos civis e políticos (primeira dimensão, direitos individuais) é conjugado, pela primeira vez, ao catálogo dos direitos econômicos, sociais e culturais (segunda dimensão). Põe-se lado a lado, de forma inédita, o valor liberdade com o valor igualdade, constituindo um marco decisivo para os direitos humanos, os quais passam a ser concebidos como uma unidade interdependente, interrelacionada e indivisível. Confirma-se, ademais, que as gerações de direitos não se superam, mas interagem. ${ }^{19}$

Dentre as diversas razões que explicam a resistência, sobretudo estatal, quanto ao reconhecimento da fundamentalidade dos direitos sociais, estão os famigerados "custos".

Com relação à teoria do custo dos direitos, a propósito, merece destaque a obra pioneira dos professores Cass Sunstein e Stephen Holmes, The cost of rights. ${ }^{20}$ No Brasil, esse importante estudo é desvendado por Flávio Galdino. $^{21}$

O objetivo fundamental dessa teoria é “demonstrar que todos os direitos são positivos, e, portanto, demandam algum tipo de prestação pública (em última análise, por parte do Estado) para sua efetivação.”22

${ }^{18}$ SARLET, Ingo Wolfgang. Dignidade da pessoa humana e direitos fundamentais na Constituição Federal de 1988. 5. ed. Porto Alegre: Livraria do Advogado, 2008.

${ }^{19}$ PIOVESAN, Flávia. A Constituição brasileira de 1988 e os Tratados Internacionais de Proteção dos Direitos Humanos. EOS. Revista Jurídica da Faculdade de Direito. v. 2. n. 1. Ano II, 2008.

${ }^{20}$ HOLMES, Stephen; SUNSTEIN, Cass. The cost of rights: why liberty depends on taxes. New York: Macmilann, 2004.

${ }^{21}$ GALDINO, Flávio. Introdução à Teoria do Custo dos Direitos: direitos não nascem em árvores. Rio de Janeiro: Lumen Juris, 2005.

${ }^{22}$ GALDINO, Flávio. Introdução à Teoria do Custo dos Direitos: direitos não nascem em árvores. Rio de Janeiro: Lumen Juris, 2005. 
Na medida em que se reputam positivos todos os direitos, os respectivos custos serão decorrência imediata à sua caracterização e influenciarão na sua própria natureza. Assim, conforme a adoção de um ou outro entendimento, isto é, conforme se considere um determinado direito em exame positivo ou negativo, subjetivo ou não, prestacional ou não, se imporá ou não o dever de uma prestação estatal, o que certamente influencia na concretização da Constituição, mormente na determinação de sua extensão.

Ademais, na medida em que todos os direitos têm custos, diante da limitação de recursos para efetivá-los, surge a necessidade inafastável de se fazerem escolhas em relação à interpretação constitucional relativa aos direitos em questão e seus respectivos custos, de onde surge a problemática da legitimidade para efetuar essas escolhas, gerando mais uma avalanche de insurgências com relação à efetivação desses direitos via judicial, por exemplo.

Mas para isso é também preciso ultrapassar a sólida barreira erguida pelo senso comum no sentido de que os direitos fulcrados diretamente na liberdade seriam puramente negativos, havendo duas razões principais para que a questão posta costume ser ignorada (pelo menos pelo pensamento jurídicopolítico norte-americano):

[...] em primeiro lugar, a ignorância de tais questões deixa encobertas as discussões acerca das opções políticas (e, por conseguinte, econômicas) subjacentes levadas a efeito pelos poderes públicos. A crença na ausência de custos de alguns direitos permite a consagração de uma orientação conservadora de proteção máxima de tais direitos (normalmente os estritamente individuais: liberdade e, principalmente, propriedade) em detrimento dos chamados sociais [...]. Em segundo lugar, também os liberais - expressão perigosa, aqui empregada no sentido de progressistas, ou promotores dos direitos humanos - de seu turno, parecem preferir deixar a questão em tela de lado. Deveras, há o receio velado de que a consciência e as discussões acerca dos custos dos direitos diminuam o comprometimento com a respectiva proteção. ${ }^{23}$

Outra investida contrária à fundamentalidade dos direitos sociais diz respeito à negação do seu caráter subjetivo (individual) ${ }^{24}$, na tentativa de impedir

\footnotetext{
${ }^{23}$ GALDINO, Flávio. Introdução à Teoria do Custo dos Direitos: direitos não nascem em árvores. Rio de Janeiro: Lumen Juris, 2005. p. 204-205.

${ }^{24}$ Sobre a distinção entre direito social objetivo e subjetivo: "O que se deve considerar, neste momento, é que há um inevitável entrecruzamento entre esses espectros no campo individual e no campo social, posto que, da mesma forma que para o direito individual, o direito social incorpora à sua
} 
que possam ser exigidos como prestação, pois estariam, ademais, submetidos à chamada reserva do possível, ou seja, vinculados necessariamente à disponibilidade de recursos financeiros. ${ }^{25}$

Com relação ao direito à saúde, especificamente, que é um importante direito social consagrado na Constituição de 1988, o próprio Supremo Tribunal Federal já reconheceu o caráter subjetivo. Há cerca de dois anos, por convocação do Ministro Gilmar Ferreira Mendes, a Corte promoveu a Audiência Pública da Saúde, que se realizou nos dias de 27, 28 e 29 de abril e 4, 6 e 7 de maio de 2009, ocasião em que foram ouvidos os especialistas na área da saúde, notadamente os gestores públicos, membros da Magistratura, do Ministério Público, da Defensoria Pública, da Advocacia da União, Estados e Municípios, além de acadêmicos, entidades e organismos da sociedade civil. Uma das mais marcantes decorrências que se verificou a partir daí foi a paradigmática decisão do Ministro Gilmar Ferreira Mendes, em Agravo Regimental em Suspensão de Antecipação de Tutela $n^{\circ}$. 175, oriunda do Ceará, firmando posicionamento da Corte no sentido de que o direito à saúde no Brasil é de natureza prestacional, universal e igualitário, implicando o estabelecimento de uma relação obrigacional entre cidadão e Estado, além do entendimento de que a responsabilidade dos entes federados é solidária e, que a não existência de protocolos do SUS prevendo o tratamento pleiteado não é motivo para a negação da tutela, tal como não o é o fato de alto custo da prestação de tais direitos. ${ }^{26}$

Fazendo uso das bases reflexivas lançadas por Sarlet, evidencia-se a força da lógica liberal-individualista quanto às previsões constitucionais de referidos direitos, tendo-se em vista que praticamente nunca se questionou o fato de a propriedade (que também traz um amplo custo ao Estado para sua manutenção - conforme a noção da teoria do custo dos direitos de Sunstein e

ordem objetiva uma titularidade, ou seja, ao direito social objetivo liga-se um direito social subjetivo atribuído aos sujeitos componentes do grupo e/ou a este diretamente como personalidade coletiva complexa que se apresenta como organização da unidade no interior da multiplicidade, onde seus membros conservam sua personalidade parcial. Isto permite distinguir a titularidade do direito social que não fica reduzida a uma unidade, seja individual ou coletiva. Esta coletividade complexa não reduz os seus membros a simples partes componentes de um 'grande' indivíduo múltiplo." BOLZAN DE MORAIS, Jose Luis. A idéia de direito social: o pluralismo jurídico de Georges Gurvitch. Porto Alegre: Livraria do Advogado, 1997. p. 46.

${ }^{25}$ SARLET, Ingo Wolfgang. Algumas considerações em torno do conteúdo, eficácia e efetividade do direito à saúde na Constituição de 1988. Revista Eletrônica de Direito do Estado (REDE). Salvador, Instituto Brasileiro de Direito Público, n. 18, abril/maio/junho, 2009. Disponível em: $<$ http://www.direitodoestado.com.br/rede.asp>. Acesso em: 10 jun. 2010.

${ }^{26}$ BRASIL. Supremo Tribunal Federal. Agravo Regimental $\mathbf{n}^{\mathbf{0}}$. 175, da $1^{\text {a }}$ Turma do Tribunal Regional Federal da $5^{\text {a }}$ Região, nos autos da apelação cível nº.408729, Ceará, 17 de março de 2010. Dje.n 76, Ementário nº. 2399-1. publicação em 30 de abril de 2010. 
Holmes) ${ }^{27}$, por exemplo, ocupar um lugar de destaque na Constituição (o mesmo ocorrendo com outros direitos), mas bastando que fossem contemplados os chamados direitos sociais, cuja efetivação depende, em geral, do aporte de recursos materiais e humanos, para que se passasse a questionar a própria condição de direitos fundamentais destas posições jurídicas. ${ }^{28}$

Em semelhante observação, Ledur também destaca “a oposi-ção políticoeconômica e o desprezo jurídico de que os direitos sociais ainda são objeto [...]." 29

Os direitos sociais, de segunda dimensão, caracterizam-se como direitos a prestações, “correspondendo à evolução do Estado de Direito, de matriz liberalburguesa, para o Estado democrático e social de Direito [...]”. Em relação à Constituição atual, afirma-se que referidos direitos prestacionais encontraram uma receptividade inédita no constitucionalismo pátrio. ${ }^{30}$

Relativamente ao caráter prestacional dos direitos sociais, Sanchís registra algumas advertências, tais como a de que (a) nem sempre os direitos genericamente considerados sociais exigirão uma prestação em sentido estrito (por exemplo, direito de greve e de liberdade sindical), ao mesmo tempo em que, (b) quando se refere direitos prestacionais em sentido estrito, quer-se indicar bens e serviços economicamente avaliáveis; do contrário, isso é, se aí se inserissem também a defesa jurídica ou a proteção administrativa, todos os direitos fundamentais mereceriam a qualificação de prestacionais, posto que, ainda que em graus diferenciados, todos exigem uma organização estatal que lhes permita o exercício. Em outras palavras, todos os direitos fundamentais, sejam sociais ou não, necessitam de uma prestação estatal em sentido amplo. ${ }^{31}$

No mesmo sentido o reforço de Leivas ao afirmar que:

\footnotetext{
${ }^{27}$ HOLMES, Stephen; SUNSTEIN, Cass. The cost of rights: why liberty depends on taxes. New York: Macmilann, 2004.

${ }^{28}$ SARLET, Ingo Wolfgang. Algumas considerações em torno do conteúdo, eficácia e efetividade do direito à saúde na Constituição de 1988. Revista Eletrônica de Direito do Estado (REDE). Salvador, Instituto Brasileiro de Direito Público, n. 18, abril/maio/junho, 2009. Disponível em: $<$ http://www.direitodoestado.com.br/rede.asp>. Acesso em: 10 jun. 2010. LEDUR, José Felipe. Direitos Fundamentais sociais: efetivação no âmbito da democracia participativa. Porto Alegre: Livraria do Advogado Editora, 2009.

${ }^{29}$ LEDUR, José Felipe. Direitos Fundamentais sociais: efetivação no âmbito da democracia participativa. Porto Alegre: Livraria do Advogado Editora, 2009. p. 69.

30 SARLET, Ingo Wolfgang. A eficácia dos direitos fundamentais: uma teoria geral dos direitos fundamentais na perspectiva constitucional. 10. ed. Porto Alegre: Livraria do Advogado, 2009. p. 185.

${ }^{31}$ SANCHÍS, Luis Prieto. Los derechos sociales y el principio de igualdad sustancial. In: BARUFFI, Helder. (Org.). Direitos fundamentais sociais: estudos em homenagem aos 60 anos da declaração universal dos direitos humanos e aos 20 da Constituição Federal. Dourados: UFGD, 2009.
} 
A primeira das características dos direitos fundamentais sociais que vem à tona é a de serem direitos a ações positivas. [...] Porém, nem todos os direitos a ações positivas são direitos fundamentais sociais. Estes formam uma espécie de direitos fundamentais prestacionais em sentido amplo, que compreendem direitos à proteção, direitos à organização procedimentos e direitos fundamentais sociais. Os direitos prestacionais em sentido amplo são direitos a ações positivas, porém cada um destes tipos de direitos tem seus caracteres próprios. Por exemplo, direitos a procedimentos e organização são direitos positivos a ações normativas do Estado. [...] Neste sentido, impende acrescentar o elemento fático ao conceito. Assim, direitos fundamentais sociais são direitos a ações positivas fáticas. Não são, porém, quaisquer ações fáticas: são aquelas que, se o indivíduo possuísse meios financeiros suficientes e, se encontrasse no mercado uma oferta suficiente, poderia obtêlas também de particulares. [...] Entretanto, nem tudo que pode ser encontrado no mercado pode ser objeto de um direito fundamental social. Agrega-se, então, o caráter da importância. ${ }^{32}$

Em apertada síntese, portanto, pode-se dizer que "o direito a prestações reduz-se ou reconduz-se ao seguinte: $O$ direito de qualquer cidadão a um acto positivo (facere) dos poderes públicos (Estado)." O conceito é amplo, envolvendo desde o direito de o cidadão exigir do Estado proteção perante outros cidadãos (por meio de normas penais, por exemplo), passando pelo direito a que o Estado atribua aos cidadãos uma posição organizatória e procedimentalmente relevante para a defesa ou exercício de outros direitos (como participação em órgãos colegiais, participação no procedimento administrativo), até chegar ao direito a prestações fáticas (subvenções, lugares na Universidade, postos de trabalho, serviços de saúde e por aí segue), aqui sim fazendo referência ao direito a prestações em sentido estrito (Leistungsrechten im engeren Sinne). O que se quer destacar é que “[...] ao contrário do que por vezes se afirma, alguns dos “típicos direitos liberais” apresentam problemas semelhantes aos dos modernos "direitos a prestações”."33

Para concluir esse ponto específico (não por esgotamento do tema, mas por se aproximarem as margens que limitam o presente estudo), é de se deixar assentado que os direitos a prestações (tanto em sentido amplo quanto restrito) "se encontram a serviço de uma concepção globalizante e complexa do ser

${ }^{32}$ LEIVAS, Paulo Gilberto Cogo. Teoria dos direitos fundamentais sociais. Porto Alegre: Livraria do Advogado, 2006. p. 87-88.

${ }^{33}$ CANOTILHO, José Joaquim Gomes. Estudos sobre direitos fundamentais. Coimbra: Coimbra Editora, 2004. p. 50-51. 
humano e de sua posição no e perante o Estado”, ancorada no pressuposto de que a proteção da liberdade e da igualdade não deve ser reduzida a uma dimensão meramente jurídico-formal. ${ }^{34}$

Como se nota, a Constituição brasileira conforma um Estado não absenteísta, no sentido de não ser neutro, tampouco indiferente, diante das necessidades de desenvolvimento econômico e social previstas no próprio texto constitucional. Na prática, isso pressupõe um Estado garantidor de determinadas prestações indispensáveis à consecução desses objetivos, radicados, conforme dito, especialmente na dignidade da pessoa humana, mas também com foco na redução das desigualdades sociais e regionais. ${ }^{35}$

O preâmbulo da Constituição de 1988 assenta a instituição de um Estado Democrático destinado a assegurar o exercício dos direitos sociais ${ }^{36}$, não se justificando, destarte, as tentativas de inferiorizar esses direitos colocando-os em uma posição subsidiária ou acessória.

A esse propósito, cumpre destacar uma particularidade da construção histórica dos direitos sociais no Brasil; conforme anotado por José Murilo de Carvalho, houve, aqui, pelo menos duas diferenças importantes nesse processo: uma maior ênfase em um dos direitos, o social, em relação aos outros; e uma alteração na sequência em que os direitos foram adquiridos, com a precedência do social. ${ }^{37}$ Portanto, estando a previsão e proteção de tais direitos vinculada a sua própria construção histórico-social no Brasil, não se justificam posições que conduzam a um retrocesso quanto a isso.

Tanto que, ao listar os valores supremos do Estado Democrático brasileiro, o constituinte não ignorou os direitos sociais (consagrados nos artigos $6^{\circ}$ a 11 do texto constitucional); ao contrário, considerou-os como categoria jurídica essencial do regime, pertencentes à mesma condição de importância dos direitos civis e políticos. Dando continuidade a esse argumento, Barretto sustenta:

\footnotetext{
${ }^{34}$ SARLET, Ingo Wolfgang. A eficácia dos direitos fundamentais: uma teoria geral dos direitos fundamentais na perspectiva constitucional. 10. ed. Porto Alegre: Livraria do Advogado, 2009. p. 188-189.

${ }^{35}$ ARAGÃO, Alexandre Santos de. Direito dos serviços públicos. Rio de Janeiro: Forense, 2007.

36 "Nós, representantes do povo brasileiro, reunidos em Assembléia Nacional Constituinte para instituir um Estado Democrático, destinado a assegurar o exercício dos direitos sociais e individuais, a liberdade, a segurança, o bem-estar, o desenvolvimento, a igualdade e a justiça como valores supremos de uma sociedade fraterna, pluralista e sem preconceitos, fundada na harmonia social e comprometida, na ordem interna e internacional, com a solução pacífica das controvérsias, promulgamos, sob a proteção de Deus, a seguinte CONSTITUIÇÃO DA REPÚBLICA FEDERATIVA DO BRASIL.” [grifo nosso]. Constituição da República Federativa do Brasil (1988). Acesso em: 30 abr 2013.

${ }^{37}$ CARVAlHO, José Murilo de. Cidadania no Brasil: o longo caminho. 11. ed. Rio de Janeiro: Civilização Brasileira, 2008. p. 11-12.
} 
O argumento que pretendo desenvolver parte de um pressuposto radical, qual seja o de que os direitos sociais não são meios de reparar situações injustas, nem são subsidiários de outros direitos. Não se encontram, portanto, em situação hierarquicamente inferior aos direitos civis e políticos. Os direitos sociais - entendidos como igualdade material e exercício da liberdade real - exercem no novo paradigma, aqui proposto, posição e função, que incorpora aos direitos humanos uma dimensão necessariamente social, retirando-lhes o caráter de “caridade” ou "doação gratuita”, e atribuindo-lhes o caráter de exigência moral como condição da sua normatividade. Constituem-se, assim, em direitos impostergáveis na concretização dos objetivos últimos pretendidos pelo texto constitucional. ${ }^{38}$

Do ponto de vista ético, para completar a fundamentação proposta aos direitos sociais no Estado Democrático de Direito, enquanto elemento que lhe sustenta, o modelo teórico kantiano satisfaz a exigência de justificação. Tomese, de início, apenas o imperativo categórico, em ambas as formulações: (1) "Procede apenas segundo aquela máxima, em virtude da qual podes querer ao mesmo tempo que ela se torne em lei universal." 39 E o imperativo prático (2): "Procede de maneira que trates a humanidade, tanto na tua pessoa como na pessoa de todos os outros, sempre ao mesmo tempo como fim, e nunca como puro meio." 40

Em resumo, o imperativo categórico tem duas formulações básicas. A primeira máxima determina, conforme visto, que para uma ação ser uma ação moral ela deve ter condições de ser aceita, ao mesmo tempo, como uma lei universal de comportamento (é preciso que se tenha condições de querer a universalização da própria ação). A segunda formulação dirá que se deve agir considerando o outro como um fim em si mesmo e não como um instrumento (e se poderia destacar já aí a raiz dos direitos sociais).

Além disso, há quem sustente ser possível ler nas entrelinhas da obra kantiana um outro tipo de imperativo (seria um imperativo jurídico categórico, expressão nunca empregada diretamente por Kant, é de se frisar), implícito, que permitiria uma abertura metodológica para o desenvolvimento da ideia de

${ }^{38}$ BARRETTO, Vicente de Paulo. O fetiche dos direitos humanos e outros temas. Rio de Janeiro: Lumen Juris. 2010. p. 195.

${ }^{39}$ KANT, Immanuel. Fundamentação da metafísica dos costumes. Tradução de António Pinto de Carvalho. São Paulo: Companhia Editora Nacional. 1964. p. 82-83.

${ }^{40}$ KANT, Immanuel. Fundamentação da metafísica dos costumes. Tradução de António Pinto de Carvalho. São Paulo: Companhia Editora Nacional. 1964. p. 90-92. 
que os direitos sociais têm caráter de universalidade obrigatória, por serem direitos encontrados nas origens da sociedade humana. ${ }^{41}$

De qualquer forma, o que se quer demonstrar é que o imperativo categórico, enquanto princípio superior da moralidade, passa a ser um instrumento de referência para a própria ação e, também, para a avaliação/ julgamento das ações dos demais agentes morais, todos livres, iguais e, sobretudo, autônomos. Aliás, a própria concepção de autonomia, central em Kant, reclama obrigatoriamente para o seu exercício uma igualdade mais que formal.

Essa é a raiz do Estado Democrático de Direito, que reconhece no ser humano, pela sua própria humanidade, um fim em si mesmo, devendo como tal ser tratado por todos e, dessa forma, negando justificação às ações contrárias a um tal imperativo (que se utilizem do indivíduo como meio e violem, desse modo, sua dignidade).

Do ponto de vista contemporâneo, a presença do fundamento ético kantiano na Constituição permite direcionar um futuro profícuo para os direitos sociais, tendo em vista que o imperativo conduz, além da correção moral (objetiva) das ações individuais, o reconhecimento da humanidade intrínseca a cada pessoa, necessariamente considerada como um fim em si mesmo. Assim, os direitos sociais, estruturados a partir dessas bases, tem condição de seguir adiante, evoluindo teórica e concretamente.

\section{CONSIDERAÇÕES FINAIS}

Não se pode negar que a construção teórica dos direitos fundamentais surge com um propósito bastante específico: limitar o poder do Estado. Para atender a essa finalidade originária, a liberdade foi privilegiada e consagrada como direito fundamental, natural a todos os homens que assim nasciam. É certo que esses mesmos homens nasceram também iguais, e as declarações de direito e Constituições desde a Revolução Francesa não se furtaram a esse reconhecimento. Mas, que igualdade é essa?

Desde há muito que a igualdade meramente formal, aquela que garante igual tratamento jurídico-legal a todos, não é suficiente para assegurar esse mesmo preceito de modo substancial. A própria liberdade fica comprometida em seu pleno exercício conforme uns tenham atendidas determinadas condições e outros não.

${ }^{41}$ BARRETTO, Vicente de Paulo. O fetiche dos direitos humanos e outros temas. Rio de Janeiro: Lumen Juris. 2010. 
Sendo assim, os direitos sociais surgem para garantir a materialidade dessa igualdade prometida há tanto tempo. Na Constituição Federal brasileira de 1988, fazem parte da estrutura pensada para o Estado Democrático almejado. Por isso as resistências que ainda persistem quanto à fundamentalidade dos direitos sociais não se justificam sob o prisma histórico e jurídico-constitucional.

Não bastasse a previsão expressa no texto (artigos $6^{\circ}$ a 11 ), o compromisso firmado pela Constituição com a dignidade da pessoa humana e, corolário, como não poderia deixar de ser, com a construção de uma sociedade livre, justa e solidária, deixa clara a posição privilegiada dos direitos sociais, tão importantes e fundamentais quanto qualquer um dos direitos civis e políticos.

Do ponto de vista ético, o modelo kantiano fornece justificativas sólidas para completar o quadro em prol da fundamentalidade e fundamentação dos direitos sociais, permitindo elenca-los, inclusive, como condição de sustentabilidade do modelo democrático proposto pelo texto constitucional. A presença do fundamento ético kantiano na Constituição impele à correção moral (objetiva) das ações individuais e ao reconhecimento da humanidade intrínseca a cada pessoa, necessariamente considerada como um fim em si mesmo, de modo que os direitos sociais encontram justificativa teórica contundente para exigibilidade e garantia. É preciso avançar na consecução desse projeto, pois indispensável o respeito e a concretização dos direitos sociais.

\section{REFERÊNCIAS}

ARAGÃO, Alexandre Santos de. Direito dos serviços públicos. Rio de Janeiro: Forense, 2007.

AVELÃS NUNES, António José. As voltas que o mundo dá... Reflexões a propósito das aventuras e desventuras do estado social. Rio de Janeiro: Lumen Juris, 2011.

BARRETTO, Vicente de Paulo. O fetiche dos direitos humanos e outros temas. Rio de Janeiro: Lumen Juris. 2010.

BÖCKENFÖRDE, Ernst-Wolfgang. Estudios sobre el Estado de Derecho y la Democracia. Madrid: Trotta, 2000. 
BOBBIO, Norberto. El tiempo de los derechos. Madrid: Sistema, 1991.

BOLZAN DE MORAIS, Jose Luis. Do Direito social aos interesses transindividuais: o Estado e o Direito na ordem contemporânea. Porto Alegre: Livraria do Advogado, 1996.

A idéia de direito social: o pluralismo jurídico de Georges Gurvitch. Porto Alegre: Livraria do Advogado, 1997.

BRASIL. Supremo Tribunal Federal. Agravo Regimental no. 175, da $1^{\text {a }}$ Turma do Tribunal Regional Federal da $5^{\text {a }}$ Região, nos autos da apelação cível nº.408729, Ceará, 17 de março de 2010. Dje.nº 76, Ementário nº. 23991. publicação em 30 de abril de 2010.

BRASIL. Constituição da República Federativa do Brasil (1988). Disponível em: <http://www.planalto.gov.br>. Acesso em: 30 abr 2013.

CANOTILHO, José Joaquim Gomes. Estudos sobre direitos fundamentais. Coimbra: Coimbra Editora, 2004.

CARVALHO, José Murilo de. Cidadania no Brasil: o longo caminho. 11. ed. Rio de Janeiro: Civilização Brasileira, 2008.

DOUZINAS, Costas. 0 fim dos direitos humanos. Traduzido por Luzia Araújo. São Leopoldo: Unisinos, 2009.

DALLARI, Dalmo de Abreu. Elementos de teoria geral do Estado. 30. ed. São Paulo: Saraiva, 2011.

GALDINO, Flávio. Introdução à Teoria do Custo dos Direitos: direitos não nascem em árvores. Rio de Janeiro: Lumen Juris, 2005.

HOLMES, Stephen; SUNSTEIN, Cass. The cost of rights: why liberty depends on taxes. New York: Macmilann, 2004.

KANT, Immanuel. Fundamentação da metafísica dos costumes. Tradução de António Pinto de Carvalho. São Paulo: Companhia Editora Nacional. 1964. 
LEDUR, José Felipe. Direitos Fundamentais sociais: efetivação no âmbito da democracia participativa. Porto Alegre: Livraria do Advogado Editora, 2009.

LEIVAS, Paulo Gilberto Cogo. Teoria dos direitos fundamentais sociais. Porto Alegre: Livraria do Advogado, 2006.

PIOVESAN, Flávia. A Constituição brasileira de 1988 e os Tratados Internacionais de Proteção dos Direitos Humanos. EOS. Revista Jurídica da Faculdade de Direito. v. 2. n. 1. Ano II, 2008.

ROSANVALLON, Pierre. La sociedad de los iguales. Barcelona: 2012.

SANCHÍS, Luis Prieto. Los derechos sociales y el principio de igualdad sustancial. In: BARUFFI, Helder. (Org.). Direitos fundamentais sociais: estudos em homenagem aos 60 anos da declaração universal dos direitos humanos e aos 20 da Constituição Federal. Dourados: UFGD, 2009.

SARLET, Ingo Wolfgang. A eficácia dos direitos fundamentais: uma teoria geral dos direitos fundamentais na perspectiva constitucional. 10. ed. Porto Alegre: Livraria do Advogado, 2009.

\section{Dignidade da pessoa humana e direitos fundamentais na} Constituição Federal de 1988. 5. ed. Porto Alegre: Livraria do Advogado, 2008.

Algumas considerações em torno do conteúdo, eficácia e efetividade do direito à saúde na Constituição de 1988. Revista Eletrônica de Direito do Estado (REDE). Salvador, Instituto Brasileiro de Direito Público, n. 18, abril/maio/junho, 2009. Disponível em: <http:// www.direitodoestado.com.br/rede.asp>. Acesso em: 10 jun. 2010.

STRECK, Lenio Luiz; BOLZAN DE MORAIS, José Luis. Ciência política e teoria do Estado. 7. ed. 2. tir. Porto Alegre: Livraria do Advogado, 2012.

Artigo recebido em: 14/02/2014 Aprovado para publicação em: 20/08/2015

Como citar: GERVASONI, Tássia Aparecida. BOLESINA, Iuri. Os Direitos Sociais como elemento de sustentabilidade e fundamentação do Estado Democrático De Direito. Revista do Direito Público. Londrina, v.10, n.2, p.127-144, mai./ago. 2015. DOI: 10.5433/1980-511X.2015v10n2p127. 